\title{
Characteristics of Ba-Doped PbS Thin Films Prepared by the SILAR Method
}

\author{
Y. GÜLEN* \\ Department of Physics, Faculty of Arts and Sciences, Marmara University, Istanbul, Turkey \\ (Received December 20, 2013; revised version March 10, 2014; in final form March 28, 2014)
}

\begin{abstract}
In this material production research, undoped and Ba-doped nanostructured $\mathrm{PbS}$ films are fabricated on glass surfaces by SILAR method. The structural, optical and morphological properties of the films are examined via scanning electron microscopy, UV-vis spectrophotometry and X-ray diffraction analysis. Scanning electron microscopy analysis revealed that Ba-doping concentration influences the size of the thin film's nanoparticles. Xray diffraction results showed that all of the thin films are in a face centered cubic structure. Optical studies, in the room temperature, revealed that the optical band gap of the films increases as Ba-doping concentration is increased. The intercept values on the energy axis in the range of $1.86 \mathrm{eV}$ and $2.12 \mathrm{eV}$ for $1 \%$ and $8 \% \mathrm{Ba}$-doped $\mathrm{PbS}$ films respectively. As a result, it is concluded that the structural, optical and morphological properties of the fabricated thin films are directly depend on the Ba doping ratio.
\end{abstract}

DOI: 10.12693 /APhysPolA.126.763

PACS: 61.05.-a, 61.05.cp, 68.55.Ln

\section{Introduction}

The optical and electrical properties of the semiconductor nanomaterials are unique and different from the bulk form materials [1-3]. Thin films are widely used in many industries for their applications as semiconductors [4]. Since new effects that are not present in bulk form samples can be observed in film form materials, lately researchers are greatly interested in the physical properties of thin films [5]. Once the dimensions of the film are thin enough to be compared with the de Broglie wavelength of the electron, the optical and electrical properties of the materials are significantly affected by the film size $[6,7]$. The focus of research on nanosize semiconductors has been limited to the optical absorption of the material [8].

Lead sulfide has a direct band gap of $0.4 \mathrm{eV}$ and its absorption coefficient continuously increases from the infrared to the visible region [9]. As the energy increases the extinction coefficient value of lead sulfide increases and reaches the maximum $\approx 3.5 \mathrm{eV}$. Later it decreases [10]. Because of these properties $\mathrm{PbS}$ is very suitable for infrared detection applications and researchers have been using it for this purpose for a long time. As semiconductors $\mathrm{PbS}$ thin films have a vast range of industrial applications [11-14]. The band gap of lead sulfide depends on the applied temperature and pressure and the nanocrystal size. Band gap tunable lead sulfide nanocrystals ranging from 0.6 to $1.7 \mathrm{eV}$ have been synthesized [15]. Various chemical deposition techniques such as chemical bath [8], electro [16], photo chemical [17] and successive ionic layer adsorption and reaction method [1820 ] have been reported in the literature for synthesizing

*e-mail: yasirgulen@gmail.com
$\mathrm{PbS}$ thin films. Chemical bath deposition and ultrasonic chemical bath deposition on glass substrates of $\mathrm{PbS}$ crystals from lead nitrate, thiourea alkaline aqueous solutions were studied.

Study reported that $\mathrm{PbS}$ obtained from static baths were formed from near spherical grains with average size of $183 \mathrm{~nm}$ while in the case of ultrasonic baths cubical particles of $257 \mathrm{~nm}$ were formed. Ultrasounds lead to an increase of crystallites size and strain [21]. In another study, using chemical bath technique at different solution temperatures and various deposition times, $\mathrm{PbS}$ nanocrystalline thin films were deposited on glass substrates. X-ray diffraction showed that the thicknesses of the obtained thin films were between $600-1000 \mathrm{~nm}$. Band gapS of thin films were reported to be $2.30-1.96 \mathrm{eV}$, respectively. It was observed that transmission of the films were decreasing as the thickness of the films were increasing [22]. Fusion method was used in order to grow Mn-doped PbS nanocrystals [23].

Comparing with other methods, successive ionic layer adsorption and reaction (SILAR), introduced in the mid1980s [24], is not only relatively simple, quick, economical but also more suitable for large area deposition of any configuration. Additionally, SILAR method is particularly useful for introduction of different dopants and developing the surface properties. Some essential parameters of the deposition such as concentration and $\mathrm{pH}$ of the precursor solutions, reaction time, bath temperature, complexing agents and the substrate materials greatly influenced the quality of the deposited $\mathrm{PbS}$ thin films, therefore optimizing them has an outmost importance.

In order to improve the properties of $\mathrm{PbS}$ many doping materials has been used and these materials are very important in semiconductor technological devices [25, 26]. But so far no detailed works have been reported on the effects of Ba doping for PbS film growth by the SILAR method. 
In this research, undoped and different concentrations of Ba-doped $\mathrm{PbS}$ thin films onto microscope glass slides are synthesized by the SILAR method and the morphological, compositional, structural and optical properties of the films are reported. SILAR method was employed for growing $\mathrm{PbS}$ nanofilms at room temperature under normal pressure. Since it was a very cheap and readily available material glass substrate was used rather than a semiconductor material. The surface morphology, crystal structure and optical properties of the undoped and Ba-doped $\mathrm{PbS}$ thin films have been investigated and compared with each other by scanning electron microscopy (SEM), UV-vis spectrophotometry and X-ray diffraction (XRD) analysis.

\section{Experimental}

SILAR is a simple, quick, and economical bottom-up process of synthesizing composite nanostructured thin films. The control of essential deposition parameters such as concentration and $\mathrm{pH}$ of the precursor solutions, reaction time, bath temperature, complexing agents and the substrate materials is easy and manageable. The synthesis of thin films by SILAR method consists of four critical steps. First step includes immersing the clean substrate into the cationic precursor. The cations of the compound to be produced are adsorbed by the substrate. Second step includes removing loose cations from the substrate surface by rinsing using distilled water. Third step includes immersing the substrate into the anionic precursor, as a result cations react with anions to yield a product [27]. Fourth and the last step include rinsing the substrate again with distilled water to remove loose material from the surface. These four steps complete one SILAR deposition cycle. In this study, SILAR was not conducted in a closed system. All chemical reagents used in the process were analytical grade, purchased from Sigma-Aldrich Company and Merck KGaA. Sulfuric acid solution $\mathrm{H}_{2} \mathrm{SO}_{4}$, distilled water $(18.2 \mathrm{M} \Omega \mathrm{cm})$, ammonium hydroxide $\left(\mathrm{NH}_{4} \mathrm{OH}\right)$, acetone $\mathrm{C}_{3} \mathrm{H}_{6} \mathrm{O}$, lead(II) acetate $\mathrm{Pb}\left(\mathrm{CH}_{3} \mathrm{COO}\right)_{2}$, thioacetamide $\mathrm{CH}_{3} \mathrm{CSNH}_{2}$. Chemical reagents were used without any further purification. Distilled water and amonium were used as solvents.

Synthesis of undoped samples involved following steps: First, (cation solution) $0.4 \mathrm{M} \mathrm{Pb}\left(\mathrm{CH}_{3} \mathrm{COO}\right)_{2}$ solution was prepared with $100 \mathrm{ml}$ double distilled water $(18.2 \mathrm{M} \Omega \mathrm{cm})$. Afterwards, in order to have a transparent and well-dissolved solution, the solution was treated with a magnetic stirrer at room temperature for a few minutes. Following the stirring $\mathrm{pH}$ value of the solution was adjusted to 5.7-6.1. Second, (anion solution) $0.4 \mathrm{M}$ $\mathrm{CH}_{3} \mathrm{CSNH}_{2}$ solution was prepared with $100 \mathrm{ml}$ double distilled water $(18.2 \mathrm{M} \Omega \mathrm{cm})$. The $\mathrm{pH}$ value of the solution was adjusted to 4.7-5.8. Once the cation and the anion solutions were ready SILAR deposition cycle was initiated. In the first step, the substrates were immersed into the cation solution and kept for $20 \mathrm{~s}$. In the second step, they were dipped into water for $80 \mathrm{~s}$. In third step, the substrates were dipped into the anion solution and kept for $20 \mathrm{~s}$. Finally again they were dipped into water for $80 \mathrm{~s}$. Rinsing water was changed in every 40 cycles. This cycle was applied for 200 times. Afterwards, in order to remove bigger and tightly bonded particles thin films were cleaned using an ultrasonic bath for 5 min. Finally, the thin films were left to dry at the room temperature for $12 \mathrm{~h}$. In order to keep the oxidation due to air at the minimum all samples were kept in a small container until the band gap calculation via UVvis spectrophotometry. As for the doped samples similar procedure was employed, however in this process different concentrations $\left(1,2,4,6\right.$, and 8 at.\%) of $\mathrm{BaCl}_{2}$ was added to $0.4 \mathrm{M} \mathrm{Pb}\left(\mathrm{CH}_{3} \mathrm{COO}\right)_{2}$ solutions. The $\mathrm{pH}$ value of the doped $\mathrm{Pb}\left(\mathrm{CH}_{3} \mathrm{COO}\right)_{2}$ solution was readjusted to $5.7-6.1$. The rest of the experiments were maintained as the same.

A Philips XL30S FEG scanning electron microscope was operated at an acceleration voltage of $15 \mathrm{kV}$ for morphological images. The crystal structures of the samples were examined by a Rigaku Smart Lab X-ray diffractometer (XRD: $\mathrm{Cu} K_{\alpha}$ radiation, $\lambda=1.540056 \AA$ ). A scan rate of $0.01^{\circ} / \mathrm{s}$ was applied to record the patterns in the $2 \theta$ range of $20-60^{\circ}$. Optical studies were conducted at room temperature by using a Perkin-Elmer lambda 35 spectrophotometer. The optical spectral range was 190-1100 nm.

\section{Results and discussion}

The surface morphology of undoped and Ba-doped PbS films were characterized by scanning electron microscopy (SEM). Figure 1 shows SEM micrographs of the undoped, $1 \%, 2 \%, 4 \%, 6 \%$ and $8 \%$ Ba doped in the films respectively. It revealed the intensive and roughness morphology of the heterostructure. It can be seen from Fig. 1 that

\section{TABLE}

Thickness of nanostructures $(\mathrm{SEM})-x 2$, thickness of the crystal (PZ, ellipsometry) $-x 3$, band gap $E_{\mathrm{g}}$ and grain size $D$ (Debye) of the films as a function of $\mathrm{Ba}$ concentration $-x 1$.

\begin{tabular}{l|c|c|c|c}
\hline \hline$x 1$ [at.\%] & $x 2[\mathrm{~nm}]$ & $x 3[\mathrm{~nm}]$ & $E_{\mathrm{g}}[\mathrm{eV}]$ & $D[\mathrm{~nm}]$ \\
\hline undoped & 48 & 21.5 & 1.77 & 18.6 \\
1 & 57 & 23.1 & 1.86 & 24.8 \\
2 & 65 & 24.8 & 1.98 & 22.4 \\
4 & 47 & 25.1 & 2.00 & 26.8 \\
6 & 84 & 26.9 & 2.08 & 27.6 \\
8 & 93 & 19.6 & 2.12 & 22.3
\end{tabular}

all the substrates are fully covered by $\mathrm{PbS}$ nanoparticles and all images show dense surfaces. By using a pixels analysing program the average grain size of the $\mathrm{PbS}$ films were calculated. The increase in the Ba concentration in the films increases the thickness of the plates. Thicknesses of the nanostructures, listed in Table, are found to be $480,570,650,475,840$ and $930 \mathrm{~nm}$ for undoped, $1 \%, 2 \%, 4 \%, 6 \%$ and $8 \%$ Ba doped films, respectively. 


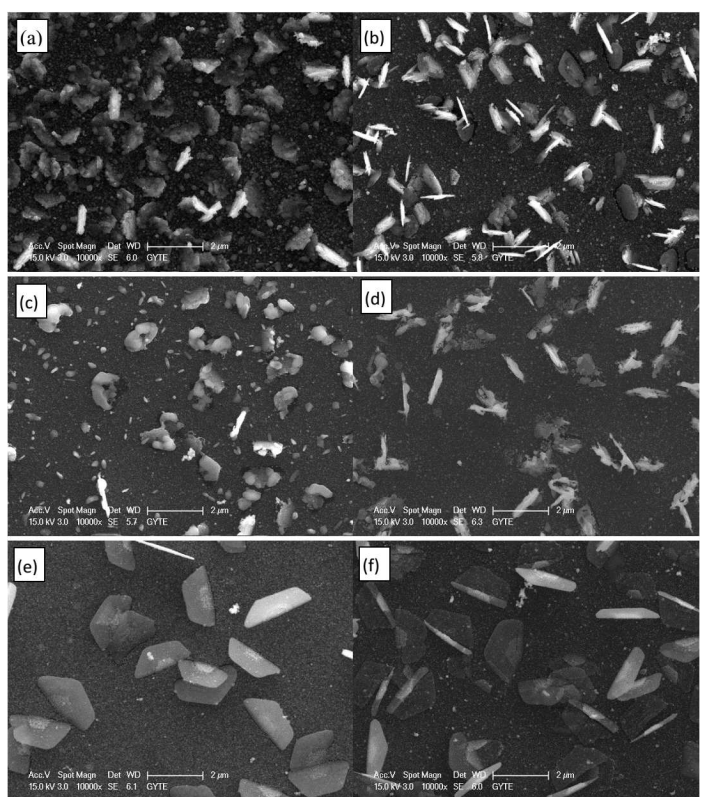

Fig. 1. SEM images of (a) undoped, (b) $1 \% \mathrm{Ba}$, (c) $2 \% \mathrm{Ba}$, (d) $4 \% \mathrm{Ba}$, (e) $6 \% \mathrm{Ba}$, and (f) $8 \% \mathrm{Ba}$ doped PbS films.

As the following sections will show, this change will affect deeply the band gap of the films. The average grain size $(D)$ of $\mathrm{Ba}$ doped $\mathrm{PbS}$ films was calculated from the peak full width at the half maximum (FWHM) of a peak $(\beta)$, using the Scherrer formula [28]:

$$
D=\frac{0.90 \lambda}{\beta \cos \theta},
$$

where $\lambda$ is the wavelength of $\mathrm{X}$-ray radiation, $\theta$ is the Bragg angle of the peaks and $\beta$ is the angular width of peaks at FWHM. Calculated average grain sizes $(D)$ of the $\mathrm{PbS}$ films are given in Table. The increase in the Ba concentration in the films decreases the grain size. Additionally, PZ 2000 ellipsometer (632.8 nm) was used for another calculation of the thickness of films.

EDS result for $8 \% \mathrm{Ba}$ concentration is provided in Fig. 2. The Ba concentrations of $4 \%, 6 \%$ and $8 \%$ in the growth solutions provided doping values of $0.02,0.04$ and 0.05 at.\% $\mathrm{Ba}$ in the films, respectively. Therefore, as the doping concentration of the growth solutions is increased the doping percentage of thin films are also increased. However, the increase of doping levels of $\mathrm{Ba}$ in the $\mathrm{PbS}$ thin films was bigger than the increase in $\mathrm{Ba}$ ions in the growth solution; that is, one unit increase in $\mathrm{Ba}$ concentration in growth solution causes more than one unit accumulation of $\mathrm{Ba}$ in fabricated $\mathrm{PbS}$ thin films.

The crystal structure and the orientation of the films have been investigated by using a Rigaku Smart Lab X-ray diffractometer (XRD: $\mathrm{Cu} K_{\alpha}$ radiation, $\lambda=$ $1.540056 \AA$ ) and the results are depicted in Fig. 3. The XRD patterns of undoped and Ba-doped $(1 \%, 2 \%, 4 \%$, $6 \%$, and $8 \%$ ) films were obtained at an operating voltage and current of $40 \mathrm{keV}$ and $30 \mathrm{~mA}$, respectively. The $2 \theta$

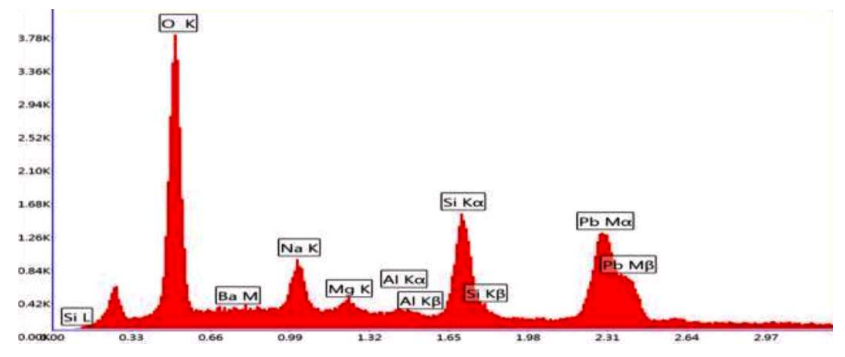

Fig. 2. EDS result for $8 \%$ Ba-doped PbS films.

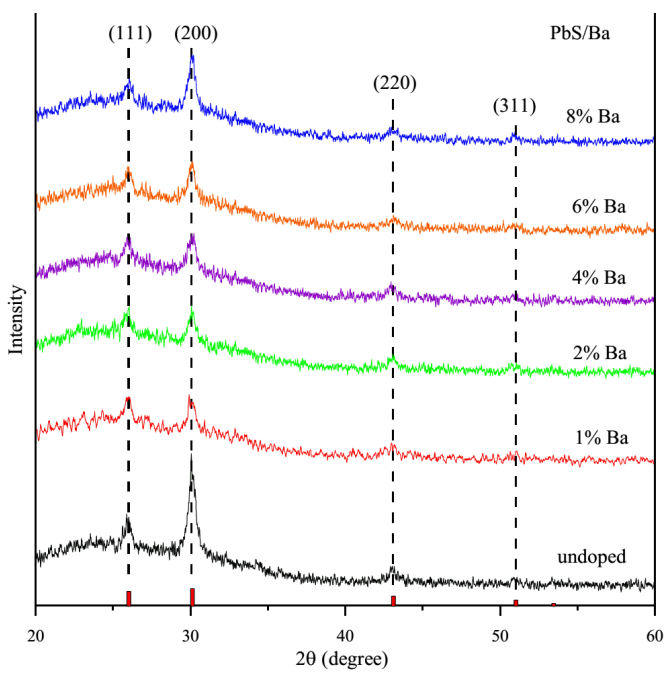

Fig. 3. X-ray diffraction patterns of undoped and Badoped PbS films.

range of $20-60^{\circ}$ was recorded at the scan rate of $0.01^{\circ} / \mathrm{s}$. From the figure it was understood that all of the films are face centered cubic structure. The peak positions were indexed to (111), (200), (220), and (311) planes and the peak positions were found to be in accordance with the JCPDS (card: 50-592) of PbS. But from the XRD data it is evident that there are no additional peaks due to $\mathrm{Ba}$ or oxides of $\mathrm{Ba}$ which means that the substitution of $\mathrm{Pb}$ atoms by $\mathrm{Ba}$ atoms has not changed the face centered cubic structure of $\mathrm{PbS}$ or the peaks belonging to $\mathrm{Ba}$ atoms were very weak that they disappeared in the noise signal. It is found that the intensities of (111) and (200) peaks are much stronger than those of other peaks which indicate that they are preferential crystal planes of the nanostructures. Ba doping caused a large decrease in the (111) and (200) peak intensities at first. But then, as the doping concentration was increased the (200) peak intensities also increased slowly. The peak (220) and (311) planes did not change significantly with the increase in Ba doping. It is evident from the XRD data that there are no extra peaks due to barium metal and other oxides, indicating that the as-synthesized samples are in single phase. The $\mathrm{Ba}$ ion was understood to have substituted the $\mathrm{Pb}$ site without changing the cubic structure. 


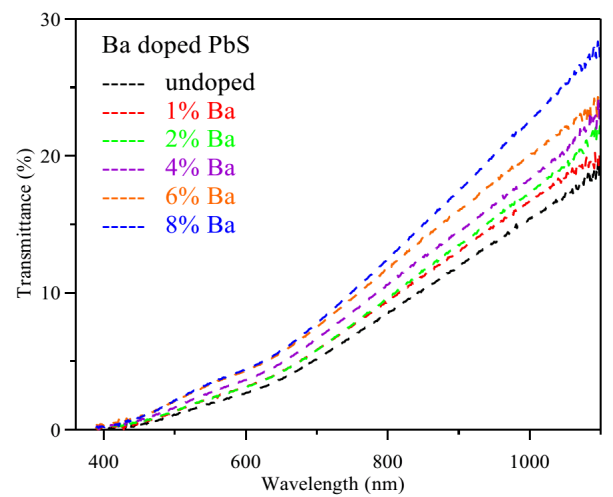

Fig. 4. Optical transmittance spectra of undoped and Ba-doped $\mathrm{PbS}$ films.

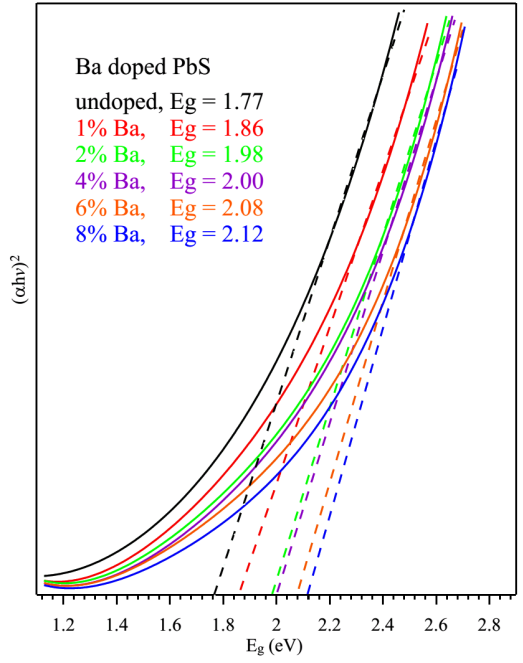

Fig. 5. Comparison of $(\alpha h \nu)^{2}$ versus $h \nu$ plots of undoped and Ba-doped PbS films.

The optical properties of pure and Ba-doped $\mathrm{PbS}$ thin films were studied to investigate the effect of doping on the optical transmittance and band gap energies. The room temperature transmission spectra of undoped and Ba-doped $\mathrm{PbS}$ thin films in the wavelength range of 400 $1100 \mathrm{~nm}$ are shown in Fig. 4. The optical transmittance of $\mathrm{Ba}$-doped $\mathrm{PbS}$ thin films increases with increase in $\mathrm{Ba}$ content. The diagram shows that transmission of undoped $\mathrm{PbS}$ thin film in $1100 \mathrm{~nm}$ up to $18 \%$ was reached. Ba incorporation to the $\mathrm{PbS}$ thin films increases the transmittance and it reaches the value of $27 \%$ at $8 \%$ Ba doping. Some studies observed and reported that as band gap of semiconductor increases, transmittance also increases [26, 29]. In order to calculate the band gap energies the absorption characteristics of the films were recorded in the wavelength range of $190-1100 \mathrm{~nm} . \mathrm{PbS}$ is known to be a direct band semiconductor. For the direct allowed transitions it is well known that the theory of optical absorption gives the relation between absorption coefficient $(\alpha)$ and photon energy $(h \nu)$ as [30]:

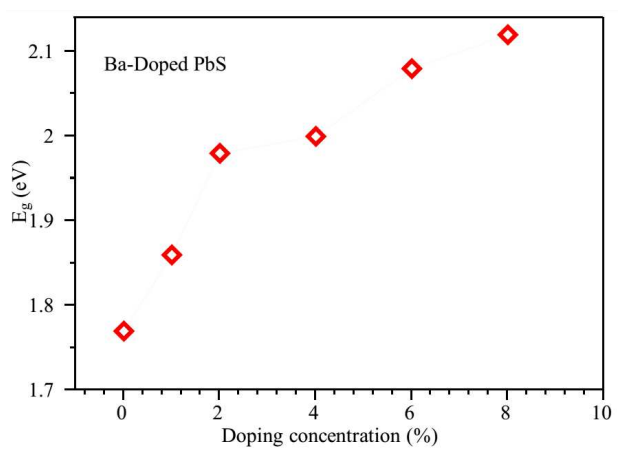

Fig. 6. Band gap values of the $\mathrm{PbS}$ films as a function of $\mathrm{Ba}$ concentration.

$$
(\alpha h \nu)^{1 / n}=B\left(h \nu-E_{\mathrm{g}}\right),
$$

where $B$ is an energy independent constant and $E_{\mathrm{g}}$ is the optical band gap of the material and the exponent $n$ depends on the type of transition. The values of $n$ for direct allowed, indirect allowed and direct forbidden transmissions are $n=1 / 2,2$ and $3 / 2$, respectively.

The direct band gaps obtained from the linear portion of $(\alpha h \nu)^{2}$ vs. $h \nu$ plot are shown in Fig. 5 as a function of Ba-doping percentages. By using this graph the direct gap values can be determined by extrapolating the straight line portion. The $E_{\mathrm{g}}$ value of undoped $\mathrm{PbS}$ film was found to be 1.77 which is in a good agreement with [26]. Just changing the dimensions of the $\mathrm{PbS}$ thin films, the band gap of the material can be increased significantly [31]. The intercept values on the energy axis were found to be 1.86, 1.98, 2.00, 2.08 and 2.12 for 1,2 , 4,6 and 8 at.\% Ba-doped $\mathrm{PbS}$ films respectively. Similarly, another study on $\mathrm{PbS}$ thin films reported an average crystallite size in the range $16-23 \mathrm{~nm}$. and the existence of band gap values in the range of $0.99-1.84 \mathrm{eV} \mathrm{[32].}$ It was found that the optical band gap was gradually increased with Ba-doping. Since the band gap of BaS $\left(E_{g}=4.25 \mathrm{eV}\right)$ [33] is higher than that of $\mathrm{PbS}$ (1.77 for the present work), the band gap of Ba-doped $\mathrm{PbS}$ should be greater than the band gap of pure $\mathrm{PbS}$. The band gap values versus Ba-doping concentrations in the growth solution are plotted in Fig. 6.

\section{Conclusion}

In this research undoped and Ba-doped $\mathrm{PbS}$ thin films were synthesized by the SILAR method. All of the films were crack free with nanosized (plate-like) particles. SEM images showed with increase of the Ba concentration in the $\mathrm{PbS}$ thin films the thickness of the plate-like nanostructures also increased. The diffraction peaks from XRD data confirms the face centered cubic structure for Ba-doped $\mathrm{PbS}$ thin films. Additionally, it is also understood that the substitution of $\mathrm{Pb}$ atoms by $\mathrm{Ba}$ atoms has not changed the face centered cubic structure of $\mathrm{PbS}$ films. According to the SEM image there are dispersed isolated planar particle on a conversional glass surface. Therefore the distance between nearest neighbors of 
particle is comparable to the size of particle so this structure can be considered as granular thin film. SEM image shows the planar structure with a size of $480-930 \mathrm{~nm}$, but the ellipsometer measurements shows the average thickness of granular thin film 19.62-26.95 nm Debye-Scherrer calculation also shows the size of crystallites fitted to the ellipsometer measurements. The optical analysis showed that the Ba-doping concentration in the films effected the transmission and optical band gap. As Ba concentration increases the optical transmission and optical band gap energy values also increase, the intercept values on the energy axis in the range of $1.86 \mathrm{eV}$ and $2.12 \mathrm{eV}$ for $1 \%$ and $8 \%$ Ba-doped $\mathrm{PbS}$ films, respectively. Ba incorporation to the $\mathrm{PbS}$ thin films increases the transmittance and it reaches the value of $27 \%$ at $8 \%$ Ba doping.

\section{Acknowledgments}

This Project is supported by Marmara University Scientific Research Projects Commissions Department under FEN-E-120613-0265 grant.

\section{References}

[1] A. Popa, M. Lisca, V. Stancu, M. Buda, E. Pentia, T. Botila, J. Opt. Adv. Mater. 8, 43 (2006).

[2] N. Choudhury, B.K. Sharma, Indian J. Pure Appl. Phys. 46, 261 (2008).

[3] R.S. Patil, H.M. Pathan, T.P. Gujar, C.D. Lokhande, J. Mater. Sci. 41, 5723 (2006).

[4] F.I. Ezema, C.E. Okeke, Acad. Open Internet J. 9, 1 (2003).

[5] C.D. Lokhande, A.U. Ubale, P.S. Patil, Thin Solid Films 1, 302 (1997).

[6] A.U. Ubale, V.S. Sangawar, D.K. Kulkarni, Bull. Mater. Sci. 30, 147 (2007).

[7] Y. Wang, A. Suna, W. Mahler, R. Kawoski, J. Chem. Phys. 87, 7315 (1987).

[8] E. Pentia, L. Pintilie, I. Matei, T. Botila, E. Ozbaya, J. Opt. Adv. Mater. 3, 525 (2001).

[9] T.H. Johnson, Proc. SPIE 60, (1983).

[10] F. Wise, Acc. Chem Res. 33, 773 (2000).

[11] S. Seghier, N. Kamoun, R. Brini, A.B. Amara, Mater. Chem. Phys. 97, 71 (2006).

[12] E. M. Larramendi, O. Calzadilla, A. Gonzalez-Arias, E. Hernandez, J. Ruiz Garcia, Thin Solid Films 389 , 301 (2001).
[13] A.P. Gaiduk, P.I. Gaiduk, A.N. Larsen, Thin Solid Films 516, 3791 (2008).

[14] J.A. Amusan, Res. J. Appl. Sci. 3, 1 (2008).

[15] A.H. Khan, U. Thupakula, A. Dalui, S. Maji, A. Debangshi, S. Acharya, J. Phys. Chem. C 117, 7934 (2013).

[16] V.C. Fernandez, E. Salvietti, F. Loglio, E. Lastraioli, M. Innocenti, L.H. Mascaro, M.L. Foresti, Appl. Electrochem. 39, 2191 (2009).

[17] M. Ichimura, T. Narita, K. Masui, Mater. Sci. Eng. $B$ 96, 296 (2002)

[18] Y. F. Nicolau, Appl. Surf. Sci. 22, 1061 (1985).

[19] J. Puisó, S. Lindroos, S. Tamulevicius, M. Leskela, V. Snitka, Thin Solid Films 428, 223 (2003).

[20] B. Güzeldir, M. Sağlam, A. Ateş, Acta Phys. Pol. A 121, 33 (2012).

[21] V. Popescu, D. Răducanu, A. Dınescu, M. Dănilă, G.L. Popescu, Chalcogen. Lett. 10, 159 (2013).

[22] M.M. Abbas, A. Ab-M. Shehab, N.-A. Hassan, A-K. Al-Samuraee, Thin Solid Films 519, 4917 (2011).

[23] R.S. Silva, P.C. Morais, H.S.L. Sullasi, W.E.F. Ayta, F.-Y. Qu, N.O. Dantas, J. Alloys Comp. 483, 204 (2009).

[24] M. Ristov, G. Saindinovski, I. Grozdanov, Thin Solid Films 123, 63 (1985).

[25] S. Abe, K. Masumoto, K. Suto, J. Cryst. Growth 181, 367 (1997).

[26] K.C. Preetha, T.L. Remadevi, Physica B 407, 4173 (2012).

[27] A.U. Ubale, D.K. Kulkarni, Indian J. Pure Appl. Phys 44, 254 (2006).

[28] A.C. Bose, P. Thangadurai, S. Ramasamy, Mater. Chem. Phys. 95, 72 (2006).

[29] Y. Gülen, F. Bayansal, B. Sahin, H.A. Çetinkara, H.S. Güder, Ceram. Int. 39, 6475 (2013).

[30] X. Yan, D. Hu, H. Li, L. Li, X. Chong, Y. Wang, Physica B 406, 3956 (2011).

[31] S. Chen, L. A. Truax, J. M. Sommers, Chem. Mater. 12, 3864 (2000).

[32] K.C. Preetha, K.V. Murali, A.J. Ragin, K. Deep T.L. Remadevi, Curr. Appl. Phys. 12, 53 (2012).

[33] S. Singh, R. Kumar, N. Singh, J. Alloys Comp. 509 L81 (2011). 